\title{
Gradience and parametric variation
}

Theodora Alexopoulou and Frank Keller

Savoirs, Textes, Langage, Lille III/RCEAL Cambridge

Informatics, University of Edinburgh

https://doi.org/10.36505/ExLing-2006/01/0011/000011

\begin{abstract}
The paper assesses the consequences of gradience for approaches to variation based on the Principles and Parameters model. In particular, the discussion focuses on recent crosslinguistic results obtained through magnitude estimation, a methodology particularly suited to the study of gradient acceptability/ grammaticality. Results on superiority and relativised minimality effects in questions are discussed in the light of current theoretical assumptions regarding the locus of crosslinguistic variation.
\end{abstract}

\section{Introduction}

Gradient grammaticality has received attention in recent years mainly due to a recent experimental methodology, magnitude estimation (Bard, Robertson and Sorace 1996, Cowart 1997) that allows the elicitation of reliable gradient acceptability judgements. The application of this methodology to crosslinguistic variation has revealed very interesting results, but also an important challenge for a parametric approach to variation, namely that, often, variation is confined to quantitative differences in the magnitude of otherwise identical principles. Here we approach the issue with particular reference to crosslinguistic studies focusing on superiority and locality violations involved in whether-islands.

\section{Basic findings on superiority and relativised minimality}

Below we summarise the results of Featherston (2004) and Meyer (2003); the former is a comparative study of superiority effects and d-linking in English and German; the latter is a comparative study between Russian, Polish and Czech. The main findings of these studies indicate:

i) A clear (statistically significant) dispreference for in-situ subjects (English, German, Russian, Polish, Czech, modulo a "reverse animacy" effect in Polish).

ii) A clear crosslinguistic effect of discourse-linking, where in-situ d-linked subjects are essentially as acceptable as other in-situ phrases.

iii) Crosslinguistically, the d-linking status of the object is irrelevant (English, German, Polish, Czech).

ExLing 2006: Proceedings of 1st Tutorial and Research Workshop on Experimental Linguistics, 28-30 August 2006, Athens, Greece 
iv) No clear interactions between arguments and adjuncts are detected (English, German, Polish, Czech, Russian).

v) Not only in-situ subjects are dispreferred, but initial subjects are also preferred (marginal effect in German, quite significant in English).

Crosslinguistic variation is confined to quantitative differences in otherwise crosslinguistically stable preferences. For example, while initial subjects are clearly preferred in English, only a marginal preference was detected in German.

A similar picture emerges from the studies of Alexopoulou and Keller (2002,2003, to appear); these studies investigate the effect of embedding (that-clauses), weak islands (whether-clauses) and strong islands (relative clauses) in questions and its interaction with the acceptability of resumption, in Greek, English and German. The main findings of these studies are summarised below.

i) A clear crosslinguistic effect of embedding under a that-clause; that is, questions extracted from a that-clause where less acceptable than non-embedded questions.

ii) A clear crosslinguistic effect of weak island violations, i.e. questions extracted from whether-clauses were significantly less acceptable than nonembedded questions. This effect, though stronger in magnitude, was similar in nature to the effect of embedding induced by that-clauses.

iii) A strong contrast between weak and strong island violations, in that, questions extracted from relative clauses induced a severe drop in acceptability; in all three languages questions violating strong islands were much worse than questions violating weak islands.

iv) Resumption is unacceptable in unembbeded questions in all three languages.

v) The acceptability of pronominals improves when they are embedded in a that-clause and a whether-clause, but not in a relative clause. Thus, there is no interaction between resumption and strong islands.

Again, crosslignuistic variation is confined to quantitative variation in the magnitude of the effects in question. For example, resumption in questions is more acceptable in Greek than in German and English; for instance, Greek unembedded questions with pronominals, though significantly worse than corresponding questions with gaps, are more acceptable than questions extracted from relative clauses (with or without pronominals). By contrast, in English and German, unembedded questions with pronominals are as bad as questions extracted from relative clauses. Further, in German, questions embedded under dass are almost as bad as questions embedded under in a weak island (whether-clause), while in English and Greek questions embed- 
ded in that-clauses are significantly better than questions embedded in weak islands.

\section{Quantitative variation and parameters}

The most important aspect of these studies is that they indicate that effects relating to superiority and relativised minimality are present crosslinguistically. In this way, these studies confirm the existence of some universal constraints where their status has either been disputed (e.g. superiority in German, Polish, Czech and Russian, whether-islands in Greek and German) or where their existence was not properly acknowledged (e.g. the fact that resumption improves weak islands in English even though such resumptives are less acceptable than gaps).

The main question we address is whether this quantitative variation should be taken at face value and modelled as such or reduced to structural differences between the languages in question, attributable to parametric variation. The former approach is advocated by Stochastic OT analyses, while, the latter, is consistent with a modular view of grammar as conceived by standard generative grammar.

We argue that, rather than taken at face value, quantitiave variation is an epiphenomenon of structural variation in the languages in question. However, at the same time, we argue that quantative variation cannot be discarded as surface "noise", of no theoretical importance, since some differences between languages are shown to be a consequence of such quantitative differences. For instance, we argue that the higher acceptability of pronominals in Greek questions is related to the availability of Clitic Left Dislocation in Greek and its absence from Greek and German. Thus, unembedded questions with pronominals are instances of CLLD where the requirement that the dislocated DP is referential/specific is violated. Such violations though, are of a semantic nature involving soft constraints (see Sorace and Keller 2004, Keller 2000) and induce milder unacceptability. By contrast, in English and German, in absence of CLLD, questions with pronominals involve violation of a hard, syntactic constraint (blocking pronominals in questions) that gives rise to strong unacceptability. This structural differentce between Greek and English is indirectly responsible for the surface fact that embedded pronominals in Greek are as acceptable as gaps but less acceptable than gaps in English. Though in both languages the acceptability of embedded pronominals improves, in Greek pronominals in questions are generally more acceptable than in English, and, thus, "closer" to the acceptability of gaps.

We further argue that locality principles underlying superiority and weak-island effects are also related to soft constraints. They only induce 
mild ungrammaticality which may be further improved by interaction with d-linking (Featherston 2004 has demonstrated experimentally the effect of dlinking on superiority violations for English and German). Further, such constraints have been argued to operate at the interface between grammar and the human sentence processor (Alexopoulou and Keller, to appear).

The consequences of this approach is the hypothesis that universal principles are generally subject to quantitative variation across languages (indirectly reducible to parametric variation) and involve interface principles, while categorical judgements are associated with parameter settings involving core grammatical phenomena. We will discuss this hypothesis with reference to further evidence from magnitude estimation studies from the domain of information structure and lexical semantics.

\section{Acknowledgements}

We are grateful to David Adger, Kook-hee Gill, John Hawkins, Napoleon Katsos, Dimitra Kolliakou, Ian Roberts, Christina Sevdali and George Tsoulas.

\section{References}

Alexopoulou Th. And Keller, F. to appear. Locality, Cyclicity and Resumption: at the interface between grammar and the human sentence processor, Language.

Bard E.G., Robertson D and Sorace, A, Magnitude Estimation for linguistic acceptability, Language 72(1).32-68.

Cowart W, 1997. Experimental Syntax, Applying objective methods to sentence judgements, Thousand Oaks, CA: Sage Publications.

Featherston F, 2004. Magnitude Estimation and what it can do for your syntax: Some wh-constraints in German. Lingua.

Keller, F. 2000. Gradience in grammar: experimental and computational aspects of degrees of grammaticality, Ph.D thesis, University of Edinburgh.

Meyer, R. 2003, Superiority effects in Russian, Polish and Checz: comparative evidence from studies on linguistic acceptability. In Proceedings of the $12^{\text {th }}$ Conference on Formal Approaches to Slavic Linguistics, Ottawa, Canada.

Sorace A and Keller, F. 2004, Gradience in Linguistic Data, Lingua. 